\title{
Informational Benefits of International Environmental Agreements
}

May 31, 2008

\author{
Amihai Glazer \\ Department of Economics \\ University of California, Irvine \\ aglazer@uci.edu \\ Stef Proost \\ Center for Economic Studies \\ KULeuven \\ stef.proost@econ.kuleuven.be
}

\begin{abstract}
Given the difficulty of monitoring, and even more so of enforcing, International Environmental Agreements, it is surprising that they are signed and implemented. This paper offers a theoretical model, which addresses this issue. The focus is on informational and coordination problems. A country which is unsure about the benefits of environmental policy may find that the benefits are higher the greater the number of other countries which lean towards taking action. Whereas each country may individually take weak environmental action, in equilibrium several countries may take strong action if they expect others to. An International Environmental Agreement can thus be selfenforcing. Such effects can appear even if international environmental spillovers are absent, and even if monitoring and enforcement are infeasible. Our approach can explain additional phenomena: why a country known to care little about the environment may deeply influence other countries if it takes strong environmental action, why lags may appear between the signing of an agreement and its implementation, and how requirements for approval by several bodies within a country can increase support for environmental action.
\end{abstract}

Keywords: Environmental policy, international agreements, signaling, regulation JEL codes: Q58, D82, L51 


\section{Introduction}

The existence of ambitious international environmental agreements (IEAs) is difficult to explain. Take climate change as an example. It is a global public bad, so that action to prevent it is a public good which can generate free riding. In addition, the benefits of reducing climate change are uncertain and, due to the thermal inertia of the oceans, come with a time lag of thirty to fifty years. Both factors make climate change action difficult to sell for politicians.

The evidence on IEA's is mixed and complex, perhaps because it is often difficult to measure the benefits and costs of IEA's. Murdoch and Sandler (1997), studying the atmospheric ozone problem related to the use of CFC's, show that the IEA mainly implements the non-cooperative equilibrium. Barrett (2003) in reviewing the making of several IEA's, presents a complex story. He draws attention to four important characteristics of IEA's. First, IEA's often take a long time to be signed. Second, IEA's are first signed by the executive but enter into force only after legislative ratification. Third, most IEA's only enter into force if the number of signatories is sufficiently large. Fourth, countries sometimes disregard the IEA they ratified.

This paper explicitly considers the uncertainty involved in environmental policies, inquiring into how the action of one country influences the beliefs of another country about the benefits of action. We see that when one country adopts a strong environmental policy, it increase the confidence in the other country that strong environmental policy would prove beneficial, and so induce that country to adopt strong environmental policy. In turn, that means that one country may be willing adopt a strong policy only if it expects the other country to. International Environmental Agreements are one means of conveying such information, and so may prove attractive to politicians, and may be selfenforcing. Section 2 reviews the literature. Section 3 sets out the main assumptions of the model. Section 4 uses a model without international spillovers to illustrate the role of an IEA as a signal for national policies. Section 5 adds international spillovers to the model. Section 6 concludes and discusses multiple political agents as a possible extension.

\section{Literature}

An extensive literature discusses international environmental agreements. It is surveyed in two recent books by Barrett $(2003,2007)$. Most of this literature considers each country as an individual player that has costs of emission reductions and suffers environmental damages. The costs are a increase with of one's own efforts; the damage increases with total emissions. Because international agreements are by nature unenforceable, most popular is the non-cooperative model: no international authority can impose efforts on countries, and countries cannot even be forced to abide by the agreements they signed. The results of this non-cooperative model are rather pessimistic, as this is a typical case of a pure public bad. Barrett (1994) considers a simple one-shot model with many identical countries and a pure public bad. He finds that in the simplest 
model, with identical countries, the number of signatories is at most three whatever the number of countries. The cooperative model allows for transfers across countries that can result in a grand coalition (Chander and Tulkens 1994). This solution, however, is difficult to enforce. Huang (2002) considers how a country's aversion to losing face by violating an international treaty can lead countries to abide with international environmental treaties. More important for this paper is that none of these models detail the internal political phase where voters and politicians have an incentive to sign an IEA.

Two strands in the literature consider both the national political process and the international negotiation process. The first strand is a theoretical analysis of the median voter model. The second strand is an empirical approach. For example, Buchholz et al. (2005) suppose the median voter determines the negotiation position of a country, followed by an international bargaining phase between countries. Their central result is that a low environmental target allows the median voter in a country to receive a larger share of gains from the bargaining game between the two countries. The result is pessimistic: despite the presence of bargaining (cooperation) between countries, the outcome is an even weaker environmental agreement than predicted by the Nash, noncooperative, outcome. This model raises several questions: it predicts very weak environmental agreements; it must assume that the bargaining outcome is enforced; it has only one political level in place: a parliament that executes the median voter's preferences. Roelfsema (2007) proposes an alternative theoretical model, showing that a decisive voter who cares sufficiently about the environment gains from delegating policy making to a politician who cares more about the environment than himself. Such delegation mitigates the risks of a 'race to the bottom' in environmental taxes.

The second strand is empirical and tries to explain the participation decisions in environmental agreements as a function of the level of democracy. No structural model is specified. Congleton (1992) finds that democracies are more willing to sign the Montreal Protocol. ${ }^{1}$ But this test is weak, because, according to Barrett (2003), the non signatories (such as Eritrea and Iraq) may be viewed as international outlaws. Murdoch et al. (2002) find that the Helsinki Protocol ${ }^{2}$ was more likely to be signed by countries that are more democratic. Frederiksson and Gaston (1999) find that democratic governments tend to sign an international agreement more quickly. Murdoch and Sandler (1996) also find that voluntary cutbacks of CFC's are higher in countries with more political freedom. Barrett (2003) is skeptical about this empirical work because the participation decision of countries are not independent: some agreements only come into force when participation exceeds a minimum number.

The benefits of environmental action can be uncertain, with people learning gradually about the damages. For a single decision maker this uncertainty raises the question whether he should delay action until more information is available (Kolstad 1996). The literature on international treaties shows how learning that affects the strategic behavior of the different countries can lead to less powerful IEA's. The conclusions (Kolstad and

\footnotetext{
${ }^{1}$ The Montreal protocol limits the emission of pollutants like CFC's which contribute to atmospheric ozone formation.

${ }^{2}$ The Helsinki protocol limits the sulfur emissions that contribute to acidification.
} 
Ulph, 2007) in this domain are rather pessimistic: learning does not make IEAs more attractive.

Here we take a different approach to learning and to IEAs. First, we assume that countries learn independently rather than collectively about the environmental problem. More importantly, in our model, a country's behavior and welfare is not only a function of the number of participants in an IEA, but also a function of the beliefs of its citizens and of the type of political agent. Environmental action (signing an IEA) by one country can signal the importance of the environmental problem; this signal can increase the participation of countries and in this way also increase the internal credibility of the environmental policy.

We will also draw upon the literature on international trade agreements, on the credibility of national policies, and on political agency theory. Maggi and Rodriguez-Clare (2007) use a model for trade negotiations where politicians rather than country preferences play a central role. International agreements are seen as a way to commit to industrial lobbies. Conconi and Perroni (2003) show how an international agreement can be enforced by a trigger strategy when the one-time gain from cheating on the agreement is sufficiently smaller than the discounted future cost of a "policy war," and how such international cooperation can strengthen the credibility of domestic policy.

We follow other work in supposing that policy can be more effective the more confident is the public that the state of nature makes the policy a good one. The essential idea that policy may lack credibility appears in works on trade protection (see Staiger and Tabellini 1987, Matsuyama 1990, and Tornell 1991). The discussion of commitment in public policy relates to work by Strotz (1955-56), Kydland and Prescott (1977), Barro and Gordon (1983), and Persson (1988). They show that current decisions of economic agents depend, in part, on their expectations of future policy. Phelps and Pollak (1968) apply the principle to determine optimal savings decisions. Alesina and Tabellini (1988) and Tabellini and Alesina (1990) extend these insights by showing that voters may favor budget deficits that constrain future public policy. Glazer (1989) applies these principles to demonstrate that collective choices will show a bias towards durable projects.

Related studies examine how expectations of a policy change may change behavior in a way that increases political support for the policy under consideration. Cassing and Hillman (1986) show that a declining industry may suddenly collapse when its small size reduces political support for protective tariffs. Obstfeld (1986) shows that a balance-ofpayments crisis can be self-fulfilling when agents expect a speculative attack to set off an inflationary domestic-credit policy. Rodrik (1991) claims that trade liberalization will succeed if it induces the growth of firms that support such liberalization. Glazer and Hassin (1998) argue that government may avoid finding that a policy will fail when such information would reduce the public's expectations that the program will be continued, and would therefore reduce private investment. 


\section{Set up of the model}

We start with a model with two countries ( $i$ and $j$ ) and no physical spillovers. Environmental spillovers will be introduced in section 5 . The politician in each country can take strong or weak environmental action, but the outcome depends in part on the credibility of his actions for the public. We use the following general timeline for the game:

1. Nature determines the state of nature (the environment), either High or Low.

2. The environment minister in each country observes an imperfect signal of the state of nature.

3. Each minister decides whether to sign an international environmental agreement, knowing what the minister in the other country does.

4. The public forms its posterior probability about the state of nature as a function of the observed political actions.

5. Each minister determines environmental policy in his country.

6. The state of the environment is realized as High or Low. The payoffs are functions of environmental policies and of the public's posterior beliefs.

We shall discuss in turn the uncertain state of nature, the actions of the ministers, the environmental benefit function and the formation of beliefs by the economic agents.

\section{$\underline{\text { Uncertain state of nature }}$}

For many environmental problems there is and was large uncertainty on the causes, the effects, and the valuation of the damages, and uncertainty about the cost of policy actions. The uncertainty is only resolved gradually. Famous examples are stratospheric ozone formation and climate change. The damaging effects of CFC's on the stratospheric ozone layer was discovered by scientists in 1974, but the different protocols restricting the emissions were only agreed to in the period 1985 to 1999 with increasingly precise estimates of the effects, benefits and costs of action. For climate change, the scientific evidence and the computation of benefits and costs of action started in the early 1990's; the uncertainty on the ultimate effects, costs and benefits of actions is still large (see Barrett 2003).

We model this uncertainty in a basic way. Policy can be strong ("Green") or weak ("Brown"). The state of nature, which determines the potential benefits of environmental policy, is uncertain. The state of nature can be either High (which makes a Green policy yield high benefits) or Low (which makes a Green policy yield low benefits). The prior probability that nature is in the High state is $\lambda$. 
Types of ministers and their actions A minister in charge of environmental policy can be either a Green $(G)$ type or else a Brown $(B)$ type; his type is common knowledge.

The minister in each country can sign or not sign an international agreement which indicates he will adopt a Green policy. And each minister, after that, adopts either a Green or a Brown policy. A Green policy has a cost $I$; a Brown policy has, ignoring environmental effects, a cost of zero.

Each minister sees a signal about the state of nature $(H$ or $L)$; the signal is correct with probability $s$. The signal seen by the two ministers may differ: even if the national scientists agree on the physical mechanisms (for climate change via IPCC), experts and policymakers may disagree about the costs of climate change, the costs of policies to reduce emissions, the redistributive effects of policies, and the political support for proposed policies. We do, however, suppose that estimates of the costs and benefits of a policy are positively correlated across countries.

\section{The payoff functions of the countries}

After the IEA is signed or not, the public in each country forms a posterior estimate, $\lambda_{p}$, that the state of nature is High. The public has a prior belief, $\lambda$, of the probability that the state of nature is High. The public's posterior belief, $\lambda_{\mathrm{p}}$, depends on this prior probability and on the behavior of the ministers in the two countries, who react to a signal on the state of nature by signing or not signing an IEA. The posterior probability of the agents is important because it determines the preventive investments (R\&D as well as green investments) by the public. One reason is that the greater the confidence in the policy's advisability, the more confident are firms or other investors (e.g., households buying cars or building houses) that the policy will be enforced, and so the more, or the earlier, they will invest. Alternatively, the public may care about environmental quality, and the more serious they think the problem is, the more is each person willing to spend on addressing the problem.

In the absence of physical spillovers, the gross benefit (before accounting for the sunk $\operatorname{cost} I$ ) for each country of adopting a Green policy is $W_{H}\left(\lambda_{p}\right)$ or $W_{L}\left(\lambda_{p}\right),{ }^{3}$ with each a non-decreasing function of its argument. The benefit only depends on the state of the environment that materializes ( $H$ or $L)$ and on the posterior probability $\lambda_{\mathrm{p}}$ used by the agents in that country. We simplify by putting $W_{L}\left(\lambda_{p}\right)=0$. In each country, the agents are homogeneous.

\section{Objective function of ministers}

Call $\lambda_{E}$ the posterior belief about the state of nature held by a minister after observing the signal on the state of nature. The value of $\lambda_{E}$ may differ from the value of the posterior

\footnotetext{
${ }^{3}$ The benefit function integrates risk attitudes.
} 
probability of the public $\lambda_{P}$ because a minister observes his own signal, but the public only observes the actions of the ministers in reaction to the signal.

The expected benefit to a Brown politician of adopting a Green policy is $\lambda_{E}\left[W_{H}\left(\lambda_{p}\right)\right]-I$. It is the expected gross benefit if the state of nature turns out to be High, multiplied by the posterior belief of the minister that the state of nature will be High, minus the cost $I$. If he does not adopt a Green policy, his expected benefit is zero.

The expected benefit to a Green politician of adopting a Green policy is $\lambda_{E}\left[W_{H}\left(\lambda_{p}\right)\right]+G-I$, where $G$ is a large positive parameter. The parameter $G$ can reflect his personal preferences or the influence of lobbying by (green) special interest group as in Dixit, Grossman, Helpman (1997).

The model can be reformulated to have the Green politician promote the general interest, whereas the Brown minister is bribed by special interest groups and has a specific utility $B$ of not signing an environmental agreement. We come back to this interpretation later.

\section{Environmental policy without environmental spillovers: Participation in environmental agreements as a signal of the state of nature}

We discuss first the model with no physical environmental spillovers between countries. This allows us to focus on the signaling effects of IEA's.

We consider three cases: ministers are Green, ministers are Brown, and one is Green while the other is Brown. Our model supposes that the different types of ministers, Green and Brown, show different biases. We can choose between two assumptions. One is that Brown ministers never adopt a Green policy, but that a Green minister who is sufficiently confident that the state of nature favors a Green policy adopts a Green policy. A Green minister would then learn nothing from the behavior of a Brown minister, but can learn from a Green minister in the other country about the likely state of nature.

The alternative assumption is that a Green minister will always favor a Green policy, but that a Brown minister will favor a Green policy only if he is sufficiently confident that the state of nature favors a Green policy. Here, a Brown minister can learn from a Brown minister, but not from a Green minister, in the other country. Analytically, it does not matter which approach we adopt. We arbitrarily choose to examine a Brown minister who may be persuaded to take action by learning what another Brown minister did. Thus, we assume that the specific utility $G$ of signing an IEA is so large, that a Green politician always signs the international environmental agreement. We shall see that, in equilibrium, a minister who signs an international environmental agreement will favor a Green policy. 


\section{PROPOSITION 1}

Let environmental spillovers between countries be absent, let the ministers' types be common knowledge, and let a Green policy be justified only when the posterior probability is based on two signals of a High state on nature. Then the outcome of the simultaneous signaling game is

1) If both ministers are Green, both sign the IEA and adopt a Green policy. Expected welfare in each country is $\lambda W_{H}(\lambda)-I$.

2) If both ministers are Brown, they sign the IEA only when the state of nature is revealed High in both countries. Expected welfare in each country is $\lambda^{2}\left\{\lambda_{E}{ }^{{ }^{\wedge}{ }^{\wedge} j} W_{H}\left(\lambda_{p}{ }^{{ }^{i}{ }^{\wedge} \mathrm{Hj}}\right)-I\right\}$,

where $\lambda_{p}^{H^{\wedge} H j}=\lambda_{E}^{H{ }^{\wedge} H j}=\frac{s^{2} \lambda}{s^{2} \lambda+(1-s)^{2}(1-\lambda)}$.

3) If one minister is Brown and the other is Green, the Green minister adopts a Green policy, and the Brown does not. Expected welfare in the country with the Green policy is $\lambda W_{H}(\lambda)-I$. Welfare in the other country is 0 .

We discuss the different cases one by one.

When both ministers are Green, both sign the IEA and adopt a Green policy. Because the public knows that Green ministers favor a Green policy regardless of the state of nature, the public's posterior probability that the state of nature is High is unaffected by the actions of the ministers and equals the prior probability $\lambda$.

When both ministers are Brown we must distinguish three cases: both saw signal $H$, both saw signal $L$, and one saw signal $H$ while the other saw signal $L$.

If both ministers saw signal $H$, the posterior probability that the state of nature is $H$ is:

$$
\lambda_{E}^{H i^{\wedge} H j}=\frac{s^{2} \lambda}{s^{2} \lambda+(1-s)^{2}(1-\lambda)}>\lambda \text { for } s>1 / 2 .
$$

By assumption, this justifies a Green policy and signing the IEA.

If both ministers saw an $L$ signal, the posterior probability that the state of nature is High is $\lambda_{E}{ }^{L i \wedge} L j=\frac{(1-s)^{2} \lambda}{(1-s)^{2} \lambda+s^{2}(1-\lambda)}$. Our assumptions imply that this does not justify a Green policy. 
The last possibility is that one Brown minister (say $i$ ) saw signal $L$ and one (say $j$ ) saw signal $H$. We have $\lambda_{E}^{H i^{\wedge} L j}=\frac{s(1-s) \lambda}{s(1-s) \lambda+s(1-s)(1-\lambda)}$. Clearly, $\lambda_{E}^{H i^{\wedge} L j}>\lambda_{E}^{L i^{\wedge} \perp j}$ : the probability that the state of nature is High is larger when one minister saw an $H$ signal than when none did. But by assumption this is insufficient for a Brown minister to adopt a Green policy. Therefore, the politicians take no action and the posterior probability is $\lambda$.

Under these assumptions, welfare may be higher when both ministers are Brown than when both ministers are Green, or than when one is Green and the other is Brown. The point is that if both Brown ministers favor a Green policy, then the public has greater confidence that the state of the environment is High than when Green ministers adopt a Green policy. More formally, the expected welfare for the different cases is

Two Green ministers: $\lambda W_{H}(\lambda)-I<0$.

Two Brown ministers: $\lambda^{2}\left\{\lambda_{E}{ }^{{ }^{\wedge} H j} W_{H}\left(\lambda_{p}{ }^{{ }^{i} \mathrm{Hj}}\right)-I\right\}>0$.

One Brown minister and one Green minister: 0 for country with Brown minister

$\lambda W_{H}(\lambda)-I<0$ for country with Green minister.

The results imply that though under Brown ministers an environmental agreement is less likely to be adopted, the increased confidence that a Green policy is adopted only when it will have large benefits makes welfare larger under Brown than under Green ministers.

Note also the benefits to Brown ministers of coordinating their actions. Neither one alone may be adopt a Green policy; but if one country expects the other to adopt a Green policy, then each adopt it. An International Environmental Agreement can provide such coordination. Moreover, such an IEA would be self-enforcing. Also note that the benefits of an IEA here arise not from direct spillovers from the environmental policy (indeed, the environmental policy may affect environmental policy only within the country which adopts it), but from informational externalities.

One should ask if an IEA is identical to a form of cheap talk. The answer, with one exception, is Yes in our case without international environmental spillovers and without economies of scale in producing abatement. The analysis we gave would apply if, instead of two countries signing an IEA, the minister in each country each announced that he would adopt a Green policy. But, as this example suggests, an IEA has an advantage over other coordination mechanisms---the negotiations can be done in secret. Thus, suppose a minister incurs a cost, even a small one, for announcing a policy that he later reverses, or for revealing that his estimate of the state of nature is wrong. Suppose that a Brown minister in country $i$ is unsure what a Brown minister in country $j$ will announce until after country $i$ makes its announcement. Then with some positive probability, country $i$ will announce a Green policy, whereas country $j$, seeing a different signal, does not adopt a Green policy. Though country $i$ could later reverse its policy, a minister who does so 
may incur a reputational cost. Therefore, ministers in the two countries may prefer to engage in secret negotiations, jointly agreeing to announce a Green policy only if both saw that the state of nature is High. The very secrecy of negotiations can make International Environmental Agreements effective and appealing.

\section{Sequential signaling}

Matters can differ if countries can act sequentially, say country $i$ setting policy before country $j$ does. If as we assumed before, one needs two independent signals that the environment needs action, then, even two Brown politicians will never adopt a Green policy and will never sign an IEA.

\section{PROPOSITION 2}

Let environmental spillovers between countries be absent, let the ministers types be common knowledge, and let Green policy be justified only when the posterior probability is based on two signals of a High state of nature. Then, the outcome of the sequential signaling game is

1) If both ministers are Green, both sign the IEA and adopt a Green policy. Expected welfare in each country is $\lambda W_{H}(\lambda)-I$.

2) If both ministers are Brown, neither signs the IEA. Welfare in each country is 0.

3) If one minister is Brown and the other is Green, the Green minister adopts a Green policy, and the Brown minister does not. Expected welfare for the country with the Green policy is $\lambda W_{H}(\lambda)-I$; welfare in the other country equals 0.

We need only to discuss the case with two Brown politicians. Suppose that a Green policy is irreversible, and can be adopted in either period 1, 2, 3 etc. Then it cannot be a Nash equilibrium for a Brown minister to adopt a Green policy in period 1---the minister could do better by delaying to period 3, making a decision only after observing whether the other country adopted a Green policy in period 2. But it is a Nash equilibrium for no country to adopt a Green policy in either period. Given that behavior, a Brown minister who sees an $H$ signal estimates the posterior probability that the state of nature is $\mathrm{H}$ as $\lambda^{H i}$, which by assumption does not justify a Green policy.

We can see here how an IEA can increase welfare by adding a minimum participation constraint before it comes into force. In our sequential setting, the Brown minister will sign if he observes $\mathrm{H}$ because he knows it will only bind him if the Brown minister in the other country also observes $\mathrm{H}$.

This story can explain why countries sign IEA's even if spillover effects are small. 


\section{International environmental spillovers}

We so far assumed that policies in a country directly affect only the citizens in that country; for a given domestic policy, no country cares what the other country does. We now extend the analysis to have environmental policy generate physical externalities, or have a direct effect: welfare in one country is higher if the other country reduces its emissions by adopting a Green policy. We will deal only with the extreme case where spillovers are complete: emissions in one country affect to the same degree the environmental quality at home and abroad. This is the case for externalities like climate change. For acid rain or tropospheric ozone formation, the spillovers are much smaller. as there the physical transport conditions (distance, wind direction etc) matter. We will also limit our discussion to the case where each minister sees a signal of a High state of nature. Only in that case does a Brown minister in each country see a Green policy as justified. As regards the behavior of the ministers, we again assume that Green ministers implement a Green policy and sign an international environmental agreement regardless of the state of nature.

We first discuss the simultaneous case. Next, we discuss sequential behavior with strategic considerations: a minister in one country may adopt a Green policy to induce the other country to adopt the same policy.

\section{The properties of the pay-off function}

The net benefit for country $i$ of adopting a Green policy will now be a function of the posterior probability formed by the minister in country $i\left(\lambda_{E}^{i}\right)$, the posterior probability formed by the public $\left(\lambda_{p}\right)$ and of the adoption or not of a Green policy by the other country:

$\lambda_{E}^{i} W_{H}\left(\lambda_{p}, x_{i}, x_{j}\right)-x_{i} I$

where $x_{i}$ is a 0,1 variable that is 1 when the country signs the environmental agreement and is 0 otherwise. As the public in each country observes the same signals (signing or not by $i$ and $j$ ), the posterior probabilities formed by the public in both countries are the same.

To contrast our results with the literature, we will discuss one extreme case where beliefs of the public do not matter at all, and one case where they do matter.

\section{Beliefs of the public do not matter}

In the case of pure public bads, non cooperation is the rule, certainly if the number of countries is large (Barrett, 1994). The following set of three assumptions guarantees that we have a non cooperative outcome, with no environmental agreement, when both ministers are Brown. 
The first assumption tells us that beliefs of the public are not important. The second assumption tells us that, if country $j$ does not sign, country also prefers not to sign. The third assumption implies that a Brown minister will not adopt a Green policy when the other country does.

$$
\begin{array}{ll}
\text { A1 } & \frac{\partial W_{H}}{\partial \lambda_{p}}=0 \\
\text { A2 } & \lambda_{E}^{H} W_{H}\left(\lambda_{p}, 1,0\right)<I \\
\text { A3 } & \lambda_{E}^{H H} W_{H}\left(\lambda_{p}, 0,1\right)>\lambda_{E}^{H H} W_{H}\left(\lambda_{p}, 1,1\right)-I
\end{array}
$$

\section{PROPOSITION 3}

In the presence of perfect environmental spillovers between countries, when the ministers' types are common knowledge, and when both ministers see a High signal for the state of nature, the outcome of the simultaneous signaling game is under assumptions A1,A2,A3:

1) If both ministers are Green, both sign the IEA and adopt a Green policy,

2) If both ministers are Brown, neither signs the IEA

3) If one minister is Brown and the other is Green, the Green minister adopts a Green policy, the Brown minister does not.

Let us discuss the cases in turn. When both ministers are Green, they both sign because of their ideological preference. This is the only way in which a cooperative solution can be reached and this is indeed an optimal solution here.

When both ministers are Brown, A2 implies that country $i$ will not sign if country $j$ does not sign and A3 guarantees that, if country $j$ signs, the best solution for $i$ is not to sign. We have a typical prisoners' dilemma here where not signing an IEA is the Nash equilibrium.

When one minister is Green, and the other Brown, he signs and in this case A3 implies that country $i$ will not sign.

Note that the ideological preference of the Green minister is here an asset rather than a drawback to reach the optimum solution.

$\underline{\text { The case where beliefs of the public do matter }}$

Now we drop Assumption A1. The Assumptions A2 and A3 no longer suffice to rule out a cooperative solution. 


\section{PROPOSITION 4}

In the presence of complete environmental spillovers between countries, when the ministers' types are common knowledge, and when both ministers see a High signal for the state of nature, the outcomes of the simultaneous signaling game under assumptions A2,A3 are

1) If both ministers are Green, both sign the IEA and adopt a Green policy,

2) If both ministers are Brown, both may sign an IEA and adopt Green policies

3) If one minister is Brown and the other is Green, the Green minister adopts a Green policy, and the Brown minister may also.

Consider in more detail outcomes when both ministers are Brown. Three possibilities arise: none signs an IEA, signing an IEA is an outcome of a coordination game, and signing the IEA is the dominant strategy.

To see this examine first whether $i$ gains from a Green policy if he expects $j$ to adopt a Green policy. The minister in country $i$ will make the following comparison:

$\lambda_{E}^{H H} W_{H}\left(\lambda_{p}^{H H}, 1,1\right)-I$ (signing) versus $\lambda_{E}^{H H} W_{H}\left(\lambda_{p}^{H}, 0,1\right)$ (not signing) and compare this with A3 that assumes: $\lambda_{E}^{H H} W_{H}\left(\lambda_{p}, 1,1\right)-I<\lambda_{E}^{H H} W_{H}\left(\lambda_{p}, 0,1\right)$

A3 does not imply that a Brown policy always dominates, because $W_{H}\left(\lambda_{p}^{H H}, 1,1\right)>W_{H}\left(\lambda_{p}, 1,1\right)$ when beliefs matter. Not joining an IEA also has the drawback that the public only sees one $\mathrm{H}$ signal instead of two.

Next, examine whether $i$ gains from a Green policy if $j$ adopts a Brown policy. This outcome appears when $\lambda_{E}^{H} W_{H}\left(\lambda_{p}^{H}, 1,0\right)-I>0$. The inequality can hold despite Assumption 2 when beliefs are unimportant $\lambda_{E}^{H} W_{H}\left(\lambda_{p}, 1,0\right)-I<0$.

Turn next to the case where one minister is Brown and the other Green. The Brown minister will sign an IEA if $\lambda_{E}^{H} W_{H}\left(\lambda_{p}^{H}, 1,1\right)-I<\lambda_{E}^{H} W_{H}\left(\lambda_{p}, 0,1\right)$. This is possible but less likely than when both ministers are Brown because the Green minister signing an IEA generates no information value for the beliefs of the public.

When both ministers are Green, they sign but the welfare outcome will be inferior to the result obtained when two Brown ministers sign. The reason is the absence of positive effects on the beliefs of the public when Green ministers sign.

Summarizing the simultaneous case, we find that the incentives to sign an IEA are clearly larger when the beliefs of the public matter for the outcome. Signing an IEA has two informational spillovers in our signaling game: it raises the posterior probability held by 
the Brown politician and held by the public that the state of nature would make a Green policy attractive. These effects may partly explain the existence of IEA's.

\section{$\underline{\text { Sequential case }}$}

When countries adopt policies sequentially, the first mover may behave strategically, recognizing that its actions can affect the other country's action. Our first goal is to demonstrate that sincere policy may not be equilibrium. To make the problem meaningful, we suppose that country $i$ moves in period 1, and country $j$ moves in period 2. Suppose, as before, that a Brown minister will sign an IEA (and adopt a Green policy) only if he is sufficiently confident that the state of nature is H. Suppose all ministers are Brown.

We can now no longer require that a Brown minister needs assurance on two High signals before he signs an IEA, as there would never be any agreement in the sequential case. We therefore assume that a Brown minister who only sees his own High signal would favor a Green policy.

Consider the case where in the first period, an L signal is observed and an $\mathrm{H}$ signal is observed in period 2. The first mover may have an incentive to misreport and sign an international agreement. This will be that case if the following inequality holds:

$$
\lambda^{L}\left[\lambda W_{H}\left(\lambda_{p}^{H H}, 1,1\right)+(1-\lambda) W_{H}\left(\lambda_{p}^{H L}, 1,0\right)\right]-I>\lambda^{L}\left[\lambda W_{H}\left(\lambda_{p}^{L H}, 0,1\right)+(1-\lambda) W_{H}\left(\lambda_{p}^{L L}, 0,0\right)\right]
$$

The left side of the inequality is the benefit of lying by signing the agreement; the right hand side corresponds to honest behavior. The signing of the agreement by the first mover increases the beliefs of the second mover, and also increases the beliefs of the public, that the state of nature is High; this increases the probability that the IEA is signed by the second country. The equilibrium must therefore have a Brown minister in period 1 adopt a Green policy with positive probability.

\section{Conclusions and extensions}

The essential element of our model is that one agent can learn from the action or preferences of another. We have been considering only two agents per country, one politician and one representative citizen. But the model can easily be extended to more agents. A direct extension is to consider more than two countries. With two countries, the

posterior probability $\lambda^{L i}$ and $\lambda^{H j}$ may not be sufficiently high to induce either country to adopt a Green policy. But if more countries independently see signals that the state of nature would make environmental policy effective, then the posterior probability (say, with three countries, $\lambda^{H i^{\wedge} \mathrm{Hj}^{\wedge} \mathrm{Hk}}$ ) can be sufficiently high to induce action.

The number of agents reporting on their signals can be increased in other ways. IEAs are commonly negotiated by the executive branch, but require ratification by the legislature in each country. If the legislature in a country sees a signal which correlates imperfectly 
with that seen by the executive, then ratification of an IEA provides further information about the state of nature. We are not here saying merely that a country is less likely to err if both the executive and the legislature must independently agree to a policy. We are making the different point that the legislature in country $i$ may be more willing to adopt a Green policy if both the legislature and the executive in country $j$ favor the IEA than if only the executive in country $j$ does.

Pursuing this reasoning, confidence in the advisability of a Green policy can also be raised when successive ministers, each seeing his own signal of the state of nature, finds that Green policy would be good. That is, the public, or the legislature, may be more willing to support a Green policy if successive ministers (either in their own country or in other countries) support a Green policy, rather than if only the incumbent minister did. Such desire for further information may cause delays in the ratification or implementation of IEA's. 


\section{References}

Barrett, Scott (1994) "Self enforcing environmental agreements." Oxford Economic Papers, 46: 878-894

Barrett, Scott (2003) Environment and Statecraft: The Strategy of Environmental TreatyMaking. New York: Oxford University Press.

Barrett, Scott (2007) Why Cooperate? The Incentive to Supply Local Public Goods. New York: Oxford University Press.

Buchholz, Wolfgang, Alexander Haupt and Wolfgang Peters (2005) "International environmental agreements and strategic voting." Scandinavian Journal of Economics, 107(1): 175-195.

Chandler, P. and H. Tulkens (1994) "A core-theoretic solution for the design of cooperative agreements on transfrontier pollution." International Tax and Public Finance, 2: 279-293.

Conconi, Paola and Carlo Perroni (2003) "Self-enforcing international agreements and domestic policy credibility."

Congleton, R.D.(1992), Political institutions and Pollution control, Review of economics and statistics, 74:412-21

Dixit, A., Grossman, G.M., Helpman, E. (1997) "Common Agency and Coordination: General Theory and Application to Government Policy Making." Journal of Political Economy, 104(4): 752-769

Frederiksson P.G., Gaston N., (1999), "The importance of trade for ratification of the 1992 climate change convention", in P.G. Frederiksson (ed.), Trade, global Policy and the Environment, World Bank Discussion Paper n402, Washington DC; World Bank, p173-189

Huang, Peter H. (2002) "International environmental law and emotional rational choice." Journal of Legal Studies, 31: S237-S258

Kolstad, C. and A. Ulph (2007) "Learning and stock effects in environmental regulations: The case of greenhouse gas emissions." Journal of Environmental Economics and Management, 31: 1-18,

Kolstad C., and A. Ulph (2007), Learning and international environmental agreements, Discussion Paper 
Murdoch, J.C. and Todd Sandler (1997) "The voluntary provision of a pure public good: The case of reduced CFC emissions and the Montreal Protocol." Journal of Public Economics, 63(3): 331-349.

Murdoch, J.C.,and W.P.M. Vijverberg, (2002), "The participation decision versus the level of participation in an environmental Treaty: A spatial probit analysis" Journal of Public Economics.

Persson T., G. Roland, and G. Tabellini (1997), "Separation of Powers and Political accountability", Quaterly Journal of Economics, 112 (4); 1163-202

Roelfsema, H. (2007) "Strategic delegation of environmental policy making." Journal of Environmental Economics and Management, 53(2): 270-275. 


\section{Notation}

$W_{H}\left(\lambda_{p}, x_{i}, x_{j}\right)$ Welfare to Brown minister in country I when state of nature is $\mathrm{H}$, posterior probability of High state of environment perceived by public is $\lambda_{\mathrm{p}}$, country $\mathrm{i}$ adopts environmental policy $\mathrm{x}_{\mathrm{i}}$ and other country adopts policy $\mathrm{x}_{\mathrm{j}}$.

I Cost of environmental policy for one country

$s$ Probability country's signal on state of nature is correct

$\lambda$ Prior probability that state of environment is High priority

$\lambda_{p}^{X Y}$ Posterior probability of the public who infers that signals to both countries have been $\mathrm{X}$ and $\mathrm{Y}$ (that can be either $\mathrm{H}$ or L)

$\lambda_{E}^{X Y}$ Posterior probability of the political agent who infers that signals to both countries have been $X$ and $Y$ (that can be either $\mathrm{H}$ or $\mathrm{L}$ ) 